\title{
PI3K Inhibitor GDC0077
}

\author{
National Cancer Institute
}

\section{Source}

National Cancer Institute. PI3K Inhibitor GDC0077. NCI Thesaurus. Code C132166.

An orally available inhibitor of phosphatidylinositol 3-kinase (PI3K), with potential antineoplastic activity. PI3K inhibitor GDC0077 binds to and inhibits various members of the PI3K family, including activating mutations in the catalytic alpha isoform PIK3CA. PI3K inhibition prevents the activation of the PI3K-mediated signaling pathway and results in the inhibition of growth and survival of PI3K-overexpressing tumor cells. Dysregulation of the PI3K signaling pathway is frequently associated with tumorigenesis and tumor resistance to a variety of antineoplastic agents and radiotherapy. PIK3CA, which encodes the p110-alpha catalytic subunit of the class I PI3K, is frequently mutated in a variety of cancer cell types and plays a key role in cancer cell growth and invasion. 